\title{
Biological Availability of Digoxin from Lanoxin Produced in the United Kingdom*
}

\author{
B. F. JOHNSON, A. S. E. FOWLE, SUSAN LADER, JENNY FOX, A. D. MUNRO-FAURE
}

British Medical fournal, 1973, 4, 323-326

\section{Summary}

Though established quality control standards were maintained, the bioavailability of digoxin from Lanoxin tablets produced in the United Kingdom fell in 1969, and was restored in 1972 . After $1.5 \mathrm{mg}$ doses of representative batches, tablets made between 1969 and 1972 produced mean values for area under the 50 hours plasma concentration/time curve of $36.6 \mathrm{ng} / \mathrm{ml} / \mathrm{hr}$ and four-day urinary excretion of $340 \mu \mathrm{g}$, compared with respective values of $67.5 \mathrm{ng} / \mathrm{ml} / \mathrm{hr}$ and $696 \mathrm{~kg}$ for recently produced tablets.

After $0.5 \mathrm{mg}$ doses of four recent independently produced batches of Lanoxin tablets no significant betweenbatch difference was found for area under the plasma concentration/time curve or cumulative urinary excretion.

Absorption of digoxin from batches of Lanoxin manufactured since May 1972 is uniform and consistent. Content uniformity is an inadequate measure of tablet quality, and consistent digoxin bioavailability cannot be ensured by existing regulations.

\section{Introduction}

Until recently the quality of digoxin tablets was assessed by the standard assay and determination of disintegration time. This situation improved with the development of methods for assessing the variation in weight of digoxin in individual tablets but since 1971 there have been indications that tablets that meet all of these requirements may vary greatly in the quantity available for gastrointestinal absorption. Investigation of bioavailability of digoxin from branded products marketed in various countries has led to several reports of differences both between brands (Lindenbaum et al., 1971; Manninen et al., 1971; Shaw et al., 1972; Binnion and McDermott, 1972) and between different production batches (Lindenbaum et al., 1971).

The recent establishment at the Wellcome Research Laboratories of digoxin radioimmunoassay techniques made it possible to assess the bioavailability of digoxin from Lanoxin tablets. It was known that a change in the manufacturing equipment had been made in 1969, and that this change had been reversed in May 1972. Though the standards for digoxin tablets in existence at these times had been fully satisfied it was decided to determine whether bioavailability had been affected by the adjustment. Subsequently, it was decided to test the consistency of bioavailability of recently produced batches of Lanoxin.

*The findings reported in this paper do not apply to Lanoxin tablets marketed in the U.S.A.

\footnotetext{
Department of Clinical Pharmacology, The Wellcome Research Laboratories, Beckenham, Kent BR3 3BS

B. F. JOHNSON, M.B., M.R.C.P., Clinical Pharmacologist A. S. E. FOWLE, M.D., M.R.C.P., Clinical Pharmacologist SUSAN LADER, B.SC., M.B., Clinical Pharmacologist JENNY FOX, Technician

A. D. MUNRO-FAURE, M.R.C.P., Clinical Pharmacologist
}

\section{Methods}

Eight healthy men volunteered for studies of blood concentration and urinary excretion of digoxin after oral administration of $0.25 \mathrm{mg}$ Lanoxin tablets from various production batches. No volunteer had a history of cardiac or renal disease, or evidence of proteinuria or glycosuria, anaemia, or abnormality of plasma urea, potassium, or calcium concentrations. The physical characteristics of the volunteers are listed in table I, and table II shows some of the analytical characteristics of the selected batches of Lanoxin, all of which were marketed. Groups of four volunteers took part in two distinct experiments.

TABLE I-Physical Characteristics of Volunteers

\begin{tabular}{c|c|c|c|c}
\hline $\begin{array}{c}\text { Subject } \\
\text { No. }\end{array}$ & $\begin{array}{c}\text { Age } \\
\text { in } \\
\text { Years }\end{array}$ & Weight (lb/kg) & Height (in/m) & $\begin{array}{c}\text { Surface } \\
\text { Area } \\
\text { (m }{ }^{2}\end{array}$ \\
\hline $\begin{array}{c}\text { Group A: } \\
1\end{array}$ & 46 & $175 / 79$ & $71 / 1.8$ & \\
2 & 24 & $176 / 80$ & $70 / 1.8$ & 1.99 \\
3 & 32 & $181 / 82$ & $73 / 1.9$ & 1.97 \\
4 & 28 & $225 / 102$ & $71 / 1.8$ & $2 \cdot 06$ \\
$\begin{array}{c}\text { Group B: } \\
5\end{array}$ & 26 & $189 / 86$ & $73 / 1.9$ & 2.21 \\
6 & 22 & $146 / 66$ & $69 / 1.7$ & 1.81 \\
7 & 37 & $195 / 88$ & $67 / 1 \cdot 7$ & 1.99 \\
8 & 26 & $144 / 65$ & $65 / 1.6$ & 1.77 \\
\hline
\end{tabular}

\section{EXPERIMENT A}

This experiment was designed to compare the bioavailability of batches 0953X and 1484X. These batches were produced between 1969 and 1972, and after May 1972 respectively.

Each volunteer received six tablets $(1.5 \mathrm{mg})$ of batch $0953 \mathrm{X}$, and an equal dose of batch $1484 \mathrm{X}$ was administered several weeks later. On each occasion six tablets were ingested after an overnight fast. Subjects sat comfortably in a warm waiting area, and were allowed only water by mouth for four hours after tablet administration. Blood samples were obtained at 15-minute intervals for two hours and at 30-minute intervals for the next two hours from a Braunula cannula inserted into a forearm vein. Further samples were obtained at $6,8,10,12,14,24,27,32,48$, 51 , and 56 hours after administration. All urine produced by each subject was collected for four days after tablet ingestion. During the first 12 hours urine collection was divided into twohour periods, but was subsequently collected in 12-hour periods.

\section{EXPERIMENT B}

This experiment was designed to compare the bioavailability of batches 1484X,1745X,1854X, and 1970X, all of which had been produced since May 1972. These batches were distinct from each other in all phases of production and manufacture, and were selected for the study without reference to the analytical results.

Each volunteer received two tablets $(0.5 \mathrm{mg})$ of Lanoxin on each of four occasions. Each received tablets from each batch, treatment administration being sequenced in accordance with a $4 \times 4$ Latin square. As in experiment $A$, tablets were ingested after an overnight fast, and the subsequent procedure was similar. Nevertheless, blood samples were obtained at 15- 
TABLE II-Characteristics of Four Batches of Lanoxin

\begin{tabular}{|c|c|c|c|c|c|c|}
\hline & Batch No.: & $0953 X$ & $1484 X$ & $1745 X$ & $1854 \mathrm{X}$ & $1970 x$ \\
\hline $\begin{array}{l}\text { Mean content of digoxin } \pm \text { S.D. }(\mu \mathrm{g}) \\
\text { Disintegration time } \\
\text { Percentage dissolution in } 60 \mathrm{~min}\end{array}$ & $\begin{array}{ll}\cdots & \cdots \\
\cdots & \cdots\end{array}$ & $234+21 \cdot 1$ & $\begin{array}{l}256 \pm 6 \cdot 7 \\
2 \min 10 \mathrm{sec} \\
98\end{array}$ & $\begin{array}{l}252 \pm 6 \cdot 6 \\
4 \mathrm{~min} 30 \mathrm{sec} \\
91\end{array}$ & $\begin{array}{l}245 \pm 8 \cdot 8 \\
4 \min _{96} 40 \mathrm{sec} \\
96\end{array}$ & $246 \underset{4 \underset{96}{\min }}{ \pm 6 \cdot 6}$ \\
\hline
\end{tabular}

minute intervals for 2.5 hours, then at 30-minute intervals for 1.5 hours, and at $6,9,24,48,56,72$, and 80 hours after administration. Further, all urine was collected for 10 days after tablet ingestion. During the first 24 hours urine collection was divided into consecutive 4-, 5-, and 15-hour periods, but was subsequently collected in 24-hour periods. A minimum of 14 days separated each treatment occasion.

\section{DIGOXIN DETERMINATION}

Digoxin was determined by a previously described radioimmunoassay method (Lader et al., 1972) in which the tracer used was an iodinated tyrosine derivative of digoxin, and antibody-bound and free digoxin were separated using a double antibody system. All samples were assayed in triplicate. Most plasma samples were assayed neat, but a $1 / 2$ dilution with bovine serum was required for an occasional sample. Plasma standards of freshly constituted freeze-dried bovine serum and three samples of reference human plasma were included in each assay run. Urine samples obtained up to eight days after tablet administration required buffer dilution varying from $1 / 5$ to $1 / 200$. Standards made up in buffer and two samples of reference human urine were included in each assay run.

\section{STATISTICAL ANALYSIS}

Differences between treatments and between subjects in each experiment were examined by analysis of variance, both parametrically and by the Friedman two-way non-parametric method.

\section{Results}

No subject experienced gastrointestinal disturbance or other symptom after any treatment.

\section{EXPERIMENT A}

Peak concentrations were significantly higher $(P<0 \cdot 01)$ after batch $1484 \mathrm{X}$, as shown in table III. The higher peak values also appeared more rapidly, the mean time to peak being 0.9 hours for $1484 \mathrm{X}$ as compared to $2 \cdot 4$ hours for $0953 \mathrm{X}$. The plasma digoxin concentration remained higher after batch $1484 \mathrm{X}$ throughout the period studied (fig. 1) The area under the curve of plasma concentration for 50 hours after each treatment was calculated by using the trapezoidal method. Areas were significantly greater $(P<0.05)$ after batch $1484 \mathrm{X}$ (table IV).

A noticeable difference in urinary digoxin excretion was also apparent. Expressed as a percentage of the administered dose,

TABLE III-Peak Plasma Digoxin Concentrations ( $\mathrm{ng} / \mathrm{ml}$ ) in Experiment $A$

\begin{tabular}{c|c|c}
\hline \multirow{2}{*}{ Subject No. } & \multicolumn{2}{|c}{ Batch No. } \\
\cline { 2 - 3 } & $0953 \mathrm{X}$ & $1484 \mathrm{X}$ \\
\hline 4 & 2.32 & 8.20 \\
1 & 2.28 & 7.23 \\
2 & 3.74 & 6.40 \\
3 & 3.22 & 4.95 \\
\hline Mean & 2.89 & 6.695 \\
\hline
\end{tabular}

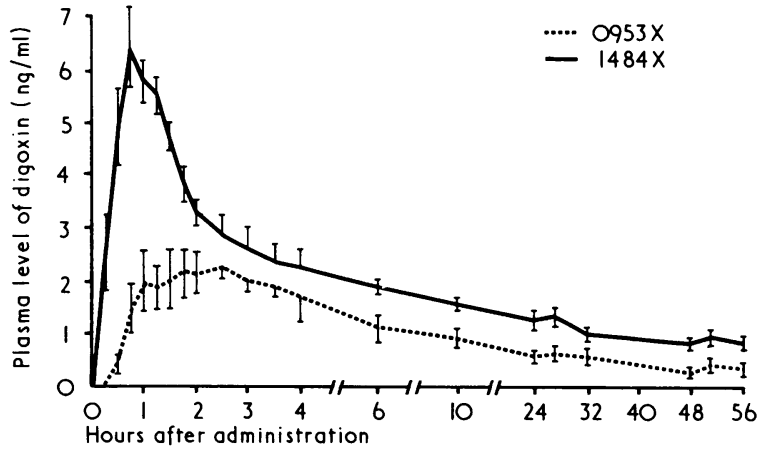

FIG. 1-Comparison of plasma digoxin concentration curves after $1.5 \mathrm{mg}$ doses of Lanoxin tablets produced between 1969 and 1972 (batch 0953X), or of recently produced tablets (batch 1484X). Mean values from four subjects and one S.E. of mean are illustrated.

TABLE IV-Area under $50 \mathrm{hr}$ Plasma Concentration/Time Curve in Experiment $A$ $(n g / m l \times h r)$

\begin{tabular}{c|c|c}
\hline \multirow{2}{*}{ Subject No. } & \multicolumn{2}{|c}{ Batch No. } \\
\cline { 2 - 3 } & $0953 \mathrm{X}$ & $1484 \mathrm{X}$ \\
\hline 4 & 19.02 & $61 \cdot 47$ \\
1 & 27.92 & $60 \cdot 28$ \\
2 & 46.97 & 62.85 \\
3 & 52.59 & 85.57 \\
\hline Mean & 36.63 & 67.54 \\
\hline
\end{tabular}

between 9 and $14 \%$ was excreted in the first 24-hour urine test after $0953 \mathrm{X}$ administration, compared with 18 to $26 \%$ after 1484X. After 48, 72, and 96 hours the respective mean cumulative values were 16,20 , and $23 \%$ for $0953 \mathrm{X}$ and 32,40 , and $46 \%$ for $1484 \mathrm{X}$. At all times these differences between batches were significant $(P<0.01)$ (fig. 2.)

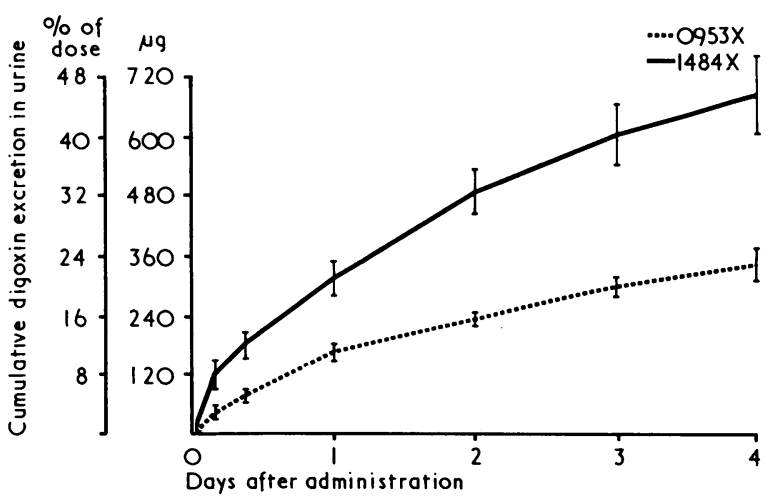

FIG. 2-Comparison in four subjects of cumulative urinary excretion of digoxin (means with S.E.) after $1.5 \mathrm{mg}$ doses of Lanoxin tablets of batch 0953X or ')atch $1484 \mathrm{X}$.

\section{EXPERIMENT B}

Moderate variability of peak concentration was observed in all subjects (table V), but no consistent difference was apparent 
between subjects or the four treatments. Variability was pronounced in one subject only in whom on one occasion a moderate plasma concentration was sustained for several hours, the maximal value of $1.2 \mathrm{ng} / \mathrm{ml}$ occurring 5.5 hours after tablet administration. No reason for this occurrence was deduced. No other instance of delayed, flattened plasma concentration curve was seen, other peak concentrations occurring between 0.5 and 2.5 hours after administration. No consistent difference in the peak time was noted between subjects or treatments. Areas under the plasma concentration curve for 80 hours were fairly consistent for each subject (table VI), and mean values were highly consistent between the four treatments.

Moderate variability in each subject's pattern of digoxin excretion was observed throughout the 10 days' urine coliection period, but there was no significant difference between subjects or treatments. Variability between subjects was obvious after batch $1745 \mathrm{X}$ only (table VII), and this was due to low urinary excretion values during the occasion in which the delayed, flattened plasma concentration curve had been noted. Mean values for percentage excretion of the administered dose of each treatment varied from 48.5 to $56.4 \%$ after 10 days.

TABLE v-Peak Plasma Digoxin Concentrations in ng/ml in Experiment B

\begin{tabular}{|c|c|c|c|c|}
\hline \multirow{2}{*}{ Subject No. } & \multicolumn{4}{|c|}{ Batch No. } \\
\hline & $1484 X$ & $1745 X$ & $1854 \mathrm{X}$ & $1970 X$ \\
\hline $\begin{array}{l}5 \\
6 \\
7 \\
8\end{array}$ & $\begin{array}{l}3.45 \\
2.70 \\
3.59 \\
3.02\end{array}$ & $\begin{array}{l}4 \cdot 34 \\
4 \cdot 42 \\
1 \cdot 21 \\
2 \cdot 90\end{array}$ & $\begin{array}{l}3 \cdot 03 \\
3 \cdot 29 \\
5 \cdot 19 \\
4 \cdot 13\end{array}$ & $\begin{array}{l}3.01 \\
2.75 \\
3.74 \\
3.36\end{array}$ \\
\hline Mean & $3 \cdot 19$ & $3 \cdot 22$ & $3 \cdot 91$ & $3 \cdot 21$ \\
\hline
\end{tabular}

TABLE vI-Area under $80 \mathrm{hr}$ Plasma Concentration/Time Curve (ng/ml x hr) in Experiment $B$

\begin{tabular}{|c|c|c|c|c|}
\hline \multirow{2}{*}{ Subject No. } & \multicolumn{4}{|c|}{ Batch No. } \\
\hline & $1484 X$ & $1745 X$ & $1854 \mathrm{X}$ & $1970 x$ \\
\hline $\begin{array}{l}5 \\
6 \\
7 \\
8\end{array}$ & $\begin{array}{l}34 \cdot 41 \\
47.58 \\
34 \cdot 18 \\
33 \cdot 48\end{array}$ & $\begin{array}{l}34.48 \\
50.95 \\
27.42 \\
39.94\end{array}$ & $\begin{array}{l}22.54 \\
48.90 \\
38.00 \\
41.86\end{array}$ & $\begin{array}{l}32 \cdot 32 \\
39 \cdot 71 \\
34 \cdot 14 \\
38 \cdot 31\end{array}$ \\
\hline Mean & $37 \cdot 41$ & $38 \cdot 20$ & 37.82 & $36 \cdot 12$ \\
\hline
\end{tabular}

TABLE VII-Cumulative Urinary Digoxin Excretion in $\mu \mathrm{g}$ in Experiment $B$ (Figures are Mean \pm S.E. of Mean)

\begin{tabular}{c|c|c|c|c}
\hline \multirow{3}{*}{ Day } & \multicolumn{4}{|c}{ Batch No. } \\
\cline { 2 - 5 } & $1484 X$ & $1745 X$ & $1854 X$ & $1970 X$ \\
\hline 1 & $122 \pm 4$ & $106 \pm 16$ & $118 \pm 4$ & $123 \pm 7$ \\
2 & $175 \pm 5$ & $157 \pm 21$ & $159 \pm 7$ & $177 \pm 8$ \\
3 & $218 \pm 10$ & $192 \pm 27$ & $188 \pm 7$ & $213 \pm 6$ \\
4 & $237 \pm 13$ & $214 \pm 28$ & $207 \pm 5$ & $237 \pm 6$ \\
10 & $282 \pm 14$ & $262 \pm 39$ & $249 \pm 12$ & $278 \pm 7$ \\
\hline
\end{tabular}

\section{Discussion}

By comparison of either peak plasma concentrations, areas under plasma concentration curves, or urinary excretion large differences were seen between batches $0953 \mathrm{X}$ and 1484X. The bioavailability of batch $1484 \mathrm{X}$ appeared to be about double that of batch 0953X. The latter batch is fully representative of Lanoxin tablets produced in the United Kingdom between 1969 and May 1972 in regard to all analytical characteristics, including rate of dissolution of digoxin content (Johnson et al., 1973). Similarly, all analytical characteristics of batch 1484X are typical of Lanoxin produced both before 1969 and since May 1972. The moderate difference in content uniformity is representative of the respective production periods, but is much too small to account for the difference in bioavailability. A similar difference in bioavailability between recently produced Lanoxin tablets and tablets made between 1969 and 1972 has been found after single doses given to volunteers and to patients on sustained treatment (Falch et al., 1973). In these studies differences in steady state values were surprisingly small, and in conflict with other reports (Stewart and Simpson, 1972; Whiting et al., 1972).

It is apparent that the bioavailability of digoxin from Lanoxin tablets produced in the United Kingdom was reduced by the manufacturing adjustment in 1969 , and that this process was reversed in May 1972. At one hospital patients taking $0.5 \mathrm{mg} /$ day of Lanoxin produced before 1969 showed steady state plasma concentrations of $1.5 \pm 0.1 \mathrm{ng} / \mathrm{ml}$ (Chamberlain et al., 1970). Nevertheless, at the same hospital, values of $0.9 \pm 0.4$ were reported for similar patients taking equal doses of Lanoxin produced after 1969 (Shaw et al., 1972). It is important to emphasize that Lanoxin tablets produced in the United Kingdom since May 1972 are equivalent in every way with those produced before 1969, as dosage recommendations are based on clinical experience with the latter. It is recommended that a doctor wishing to prescribe Lanoxin to a pátient who has never previously received digoxin should follow the well-established regimen, with an expected daily maintenance dosage between 0.25 and $0.5 \mathrm{mg}$. In countries supplied with Lanoxin tablets produced in the United Kingdom, physicians were warned of the increased bioavailability of recent tablets to prevent a sudden and potentially dangerous increase in absorption in patients already well controlled with Lanoxin. As in the past, it is expected that doctors will adjust dosage according to clinical response. In any patient showing evidence of poor control and no signs of toxicity, progressive increase in daily dosage up to 0.5 $\mathrm{mg}$ is recommended. A few patients will require a higher dosage.

Plasma concentration response and cumulative urinary excretion after administration of recently produced Lanoxin tablets resemble those reported after administration of radiolabelled digoxin in alcoholic solution (Doherty et al., 1961; Beermann et al., 1972). The rapid development of a prominent peak plasma concentration is followed by phases of rapid and slow decline. The rapid phase represents various distribution and elimination processes, and must be highly complex. From six hours after administration the slow decline of plasma digoxin shows first-order characteristics and represents elimination, predominantly by urinary excretion. The rate of elimination in this phase was consistent with previous reports, half life values ranging between 30 and 40 hours. As the assay is most precise in the concentration range of 1 to $4 \mathrm{ng} / \mathrm{ml}$, most confidence can be placed on the urinary measures of digoxin elimination rate. Pharmacokinetic conclusions are also limited by finding that cardioactive metabolites are measured with digoxin in the immunoassay (Stoll, 1972).

A much lower peak plasma digoxin concentration was shown after Lanoxin produced between 1969 and 1972 than after Lanoxin produced before and after this period. It has been suggested that less risk of transient intoxication would be associated with tablets producing lower peaks (Falch et al., 1973). Nevertheless, others have argued that clinical effects are dependent on the digoxin concentration at receptor sites rather than in plasma (Hamer and Chamberlain, 1973). It is probably only in the steady state that clinical effect relates to plasma concentration. Maximal inotropic and chronotropic effects occur several hours after either oral or intravenous digoxin in man (Gold et al., 1953; Weissler et al., 1966; Shapiro et al., 1970), presumably after tissue-plasma equilibrium has been established. It is also reassuring that high peak concentrations occur only after tablets are taken in the fasting state (White et al., 1971).

The existence of branded and generic tablets of varying bioavailability appears to be a problem with many drugs other than digoxin (Smith, 1972). As assessment of clinical efficacy is usually crude, it is fortunate that most drugs have a large therapeutic ratio. Nevertheless, small alterations in dosage of digoxin may result in either unacceptable loss of effect or intoxication. In the United States a seven-fold difference in peak plasma 
digoxin concentrations was found after the same dose of different products (Lindenbaum et al., 1971). This degree of difference must cause clinically important change if one manufacturer's product is replaced by another. A similar situation is almost certain to exist in other countries. In the United Kingdom Shaw et al. (1972) showed that mean plasma digoxin concentrations of patients in the steady state were similar whether taking Lanoxin produced between 1969 and 1972 or taking digoxin tablets other than Lanoxin. Differences between brands other than Lanoxin would not be apparent in this study. Similarity between two other brands and Lanoxin produced between 1969 and 1972 was also suggested (Hibble et al., 1972). It may be inferred that many digoxin products on the British market are of low bioavailability, but there is little information on most of the more than 20 individual brands. Evidence of large difference in dissolution rates between many branded tablets has been presented (Beckett and Cowan, 1972). Until there is reliable information on the relative true potency of digoxin preparations we think it is most unwise to prescribe unspecified digoxin tablets. If a patient adheres to one branded product there will be less risk of sudden change in clinical response.

We have shown that the bioavailability of digoxin from four different batches of recently produced Lanoxin tablets was consistent. Differences in peak plasma digoxin concentrations occurred in some subjects after treatment with different batches, but areas measured under plasma concentration/time curves over many hours showed less variation. Differences in bioavailability between batches of certain branded products may be explained by low content uniformity of the tablets (Vitti et al., 1971; van Oudtshoorn, 1972), but this could not explain the differences between brands conforming to high standards of content uniformity. Our own experience is that major change in bioavailability can occur without dramatic reduction in content uniformity, and that enforcement of existing regulations in regard to content uniformity would not ensure uniformity of digoxin bioavailability.

\section{References}

Beckett, A. H., and Cowan, D. A. (1972). Pharmaceutical fournal, 209, 133. Beermann, B., Hellström, K., and Rosén, A. (1972). Clinical Science, 43, 507. Beermann, B., Hellström, K., and Rosén, A. (1972). Clinical

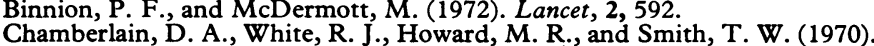
British Medical Fournal, 3, 429.

Doherty, J. E., Perkins, W. H., and Mitchell, G. K. (1961). Archives of Internal Medicine, 108, 531 .

Falch, D., Teien, A., and Bjerkelund, C. J. (1973). British Medical fournal, 1,695 .

Gold, H., et al. (1953). Journal of Pharmacology and Experimental Therapeutics, 109,45 .

Hamer, J., and Chamberlain, D. A. (1973). British Medical fournal, 2, 177. Hibble, A. G., Isaac, P., and Grahame-Smith, D. G. (1972). Lancet, 290. Johnson, B. F., Greer, H., McCrerie, J., Bye, Carole, and Fowle, A.S. E. (1973). Lancet, 1, 1473.

Lader, S., Court, G., Johnson, B. F., and Hurn, B. A. L. (1972). Scandinavian Fournal of Clinical and Laboratory Investigation, 29, Suppl. No. 126.

Lindenbaum, J., Mellow, M. H., Blackstone, M. O., and Butler, V. P. (1971). New England fournal of Medicine, 285, 1344 .

New England fournal of Medicine, 285, 1344.
Manninen, V., Melin, J., and Hartel, G. (1971). Lancet, 2, 934.

Manninen, V., Melin, J., and Hartel, G. (1971). Lancet, 2, 934. 1065 .

Shaw, T. R. D., Howard, M. R., and Hamer, J. (1972). Lancet, 2, 303.

Smith, R. N. (1972). Lancet, 2, 528.

Stewart, M. J., and Simpson, E. (1972). Lancet, 2, 541

Stoll, R. G. (1972). Research Communications in Chemical Pathology and Pharmacology, 4, 503.

van Oudtshoorn, M. C. B. (1972). Lancet, 2, 1153.

Vitti, T. G., Banes, D., and Byers, T. E. (1971). New England fournal of Medicine, 285, 1433.

Weissler, A. M., Snyder, J. R., Schoenfeld, C. D., and Cohen, S. (1966). American fournal of Cardiology, 17, 768.

White, R. J., Chamberlain, D. A., Howard, M., and Smith, T. W. (1971). British Medical fournal, 1,380 .

Whiting, B., Rodger, J. C., and Sumner, D. J. (1972). Lancet, 2, 922.

\title{
Combined Test for Assessment of Anterior Pituitary Function
}

\author{
P. HARSOULIS \\ J. C. MARSHALL, \\ S. F. KUKU, \\ C. W. BURKE, \\ D. R. LONDON, \\ T. R. FRASER
}

British Medical fournal, 1973, 4, 326-329

\section{Summary}

A combined test consisting of the simultaneous administration of insulin, thyrotrophin-releasing hormone (TRH), and luteinizing hormone and follicle stimulating hormone-releasing hormone (LH/FSH-RH) was performed in 24 people. Eleven of these also had the three individual tests performed separately, and the remaining 13 had a separate test of either LH/FSH-RH and TRH together or singly at a later date. In both normal people and patients, whether the tests were performed alone or in combination, no difference was found between the

\footnotetext{
Endocrine Unit, Department of Medicine, Royal Postgraduate Medical School, London W12 0HS

P. HARSOULIS, M.D., Research Fellow

S. F. KUKU, M.SC., M.R.C.P., Research Fellow

C. W. BURKE, D.M., M.R.C.P., Senior Registrar (Present appointment: Consultant Physician, The Radcliffe Infirmary, Oxford)

T. R. FRASER, M.D., F.R.c.P., Professor of Clinical Endocrinology
}

Queen Elizabeth Hospital, Edgbaston, Birmingham B15 2TH

J. C. MARSHALL, M.D., M.R.C.P., Lecturer in Endocrinology

D. R. LONDON, D.M., F.R.C.P., Consultant Physician hormone responses (growth hormone, cortisol, LH, FSH, thyroid-stimulating hormone) seen to these stimuli.

It is proposed that combined administration of insulin and the hypothalamic releasing hormones may be used as a single test for the assessment of anterior pituitary function. The test is convenient and time saving, and with care can be performed in outpatients.

\section{Introduction}

Measurement of growth hormone $(\mathrm{GH})$ and cortisol during insulin-induced hypoglycaemia are commonly used to assess pituitary secretion of GH and adrenocorticotrophin (ACTH) (Greenwood et al., 1966). Stimulation by the recently introduced hypothalamic releasing hormones, thyrotrophin-releasing hormone (TRH) and luteinizing hormone/follicle stimulating hormone-releasing hormone (LH/FSH-RH), now allows "pituitary reserve" for these trophic hormones to be evaluated.

Thyroid-stimulating hormone (TSH) secretion after synthetic TRH has been extensively studied both in normal people and in patients with hypothalamic-pituitary disease (Fleischer et al., 1970; Anderson et al., 1971; Haigler et al., 1971; Ormston et al., 1971; Gual et al., 1972; Hall et al., 1972). Similarly LH and FSH responses to synthetic LH/FSH-RH have been 